\title{
CONSTITUIÇÃo RADICAL: UMA IDEIA E UMA PRÁTICA
}

\section{RADICAL CONSTITUTION: AN IDEA AND A PRACTICE*}

\author{
Vera Karam de Chueiri**
}

RESUMO: $O$ artigo trata da possibilidade de uma Constituição radical e, assim, de uma possível mediação para a ação política, através da Constituição: não exatamente da norma básica, não do texto que a revela, mas também isso, na medida em que a Constituição não se deixa reduzir ao (poder) constituído, mas nela retém o poder constituinte e, desta forma, nos constitui, radicalmente, como comunidade política. Neste sentido, o trabalho discute o poder constituinte, o poder soberano e os poderes constituídos, como também o Estado de exceção e o papel das recentes manifestações de protesto.

PALAVRAS-CHAVE: Constituição. Soberania. Poder constituinte.

ABSTRACT: This article is on the possibility of a radical constitution and then on a possible mediation for political action by means of the Constitution: not exactly the basic norm, not the text that unfolds it, but also that, as far as the Constitution do not let reduce itself to the constituted (power), yet it retains in itself the constituent power and, then, radically constitutes ourselves as a political community. In this sense this work discusses constituent power, sovereign power and constituted powers, as well as the state of exception and protest and the role of recent protest manifestation.

KEYWORDS: Constitution. Sovereignty. Constituent power.

* Este artigo resulta, inicialmente, da comunicação apresentada em parceria com a prof ${ }^{a}$ Katya Kozicki, no evento sobre Política Radical e o Direito, em 2012, na PUCRJ, feito em conjunto com o Birkbeck College, de Londres, sob a coordenação da prof ${ }^{a}$ Bethania Assy e do prof. Costas Douzinas. Posteriormente, resulta da minha intervenção no evento Cidades Rebeldes, organizado pelo PAR (Partido Acadêmico Renovador), da Faculdade de Direito da UFPR, na mesa Democracia e Ação Política no Estado de Exceção, que tive o prazer de dividir com o prof. André Macedo Duarte e o prof. Rafael Barros Vieira. Sublinho que é um trabalho ainda em elaboração e, portanto, aberto à discussão. No seu atual estágio, qualquer conclusão é precária e sujeita a revisões e reelaborações.

** Professora Associada dos Programas de Graduação e Pós-Graduação em Direito da UFPR. Do Programa de Pós-Graduação em Políticas Públicas da UFPR. Coordenadora do Núcleo de Constitucionalismo e Democracia.E-mail: vkchueiri@uol.com.br 


\section{INTRODUÇC̃̃̃}

O professor Paulo Arantes afirmou, em sua intervenção no evento Cidades Rebeldes $^{1}$, que a iniciativa política não pode descartar as mediações sem ser demonizada. De fato, eu concordo com ele, toda ação política não mediada é quase que imediatamente tomada como violência, excesso, abuso e que, por isso, se identifica com o demônio. Quero ficar, por enquanto, com esta metáfora (do demônio), pois mais tarde farei referência ao texto do professor Slavoj Zizek (2013, p. 102), intitulado Problemas no paraíso. Forçando o argumento do professor Paulo Arantes, eu diria que uma ação política sem mediações retém uma radicalidade interessante, porém não necessariamente insurrecional no sentido por ele dito.

Desta forma, aproveitando a deixa e pensando no tema da ação política no Estado de exceção, quero explorar a ideia da possibilidade de uma Constituição radical e, assim, de uma possível mediação para a ação política através da Constituição: não exatamente da norma promulgada em 1988, não do texto que a revela, mas também isso, na medida em que a Constituição não se deixa reduzir ao constituído, mas nela retém o poder constituinte e desta forma nos constitui, radicalmente, como comunidade política.

É notável que, em seu livro Extinção, no capítulo sobre o estado de sítio, o professor Paulo Arantes (2007, p. 153-154) se refira a este como

o regime jurídico excepcional a que uma comunidade política é submetida, por motivo de ameaça à ordem pública, durante o qual se conferem poderes extraordinários às autoridades governamentais, ao mesmo tempo em que se restringem ou suspendem as liberdades públicas e certas garantias constitucionais.

Ou seja, o próprio autor reconhece que nesse estado há restrição e suspensão de direitos e garantias e que tal fato representa uma fratura na vida da comunidade política.

O vínculo entre Constituição e poder constituinte é tanto contingente (eventual, porém, necessário e inevitável) quanto imanente à própria ideia de Constituição. Isso implica não reduzirmos a constituinte (promessa) e a Constituição (real efetivação) aos termos de uma lógica dual (outro mundo/este mundo). Eis a minha premissa, a qual, desde o início, desconstrói a crença ingênua (facilmente encontrada nos manuais de direito constitucional) de que a Constituição é um texto ou outra, mais ingênua ainda, de que suas normas apaziguam as tensões do campo

1 Evento ocorrido em novembro de 2013, na Faculdade de Direito UFPR, organizado pelo Partido Acadêmico Renovador - PAR. 
da política e, por fim, de que basta constitucionalizar as diversas relações que se estabelecem na sociedade (políticas, econômicas, ambientais, laborais, familiares, etc.) e elas se realizarão da maneira prescrita pela norma constitucional, de forma que a promessa se cumpriu e, assim, viveremos uma realidade livre das tensões, como se fosse o paraíso.

Há um sentido agônico ou agonista na política que é preciso ser explorado na Constituição. Parafraseando Chantal Mouffe (2000, p. 99), precisamos de uma Constituição capaz de capturar a natureza (agonista) do político, uma Constituição radical.

Zizek (2013, p. 101-108) intitula seu texto, no livro Cidades Rebeldes, de Problemas no paraíso e nele afirma que "problemas no Inferno parecem compreensíveis e indaga por que é que há problemas no Paraíso?" (2013, p. 102). Parafraseando o autor, eu diria que problemas em Estados de exceção, relativamente à restrição e suspensão de direitos, como de fato foi o período da última ditadura brasileira, após o golpe de Estado de 1964 produzido pelos militares, são compreensíveis. Porém, indago por que há problemas dessa ordem, em Estados democráticos constitucionais, como o que se instituiu no Brasil, a partir da abertura política em 1985 e, especialmente, após a promulgação da Constituição em 1988? Ainda, Ruy Braga (2013, p. 81-82), que também participa do livro Cidades Rebeldes, afirma que "a questão da efetivação e a ampliação dos direitos sociais é a chave para interpretarmos a maior revolta popular da história brasileira". Por sua vez, Raquel Rolnik (2013, p. 08) fala do "direito a ter direitos que alimentou as lutas dos anos 1970 e 1980 e inspirou a Constituição e a emergência de novos atores no cenário político". Vale dizer, contra a compreensão mais imediata de que quando as liberdades básicas são cerceadas estamos diante de um Estado excepcional, há a dificuldade de vislumbrarmos (e compreendermos) porque, na vigência das liberdades básicas e dos demais direitos fundamentais, também podemos estar diante de um Estado excepcional.

Desta forma, minha reflexão começa com essa promessa que é uma Constituição radical; esse indeterminado absoluto (CAPUTO, 1997, p. 161), com esse futuro estrutural, um futuro sempre por vir, a venir, to come, a acontecer. A estrutura desse por-vir, to-come, desse a venir, desse futuro absoluto ou dessa promessa (estamos falando da Constituição), que em princípio pode não acontecer, significa a própria abertura do presente, a qual torna impossível que o mesmo se encerre num círculo e se feche em torno de si. A promessa, dessa perspectiva que quero chamar de messiânica, é a estrutura desse por-vir, a acontecer, a venir, tocome, que expõe a contingência e a desconstrução do presente. A isso que Derrida 
sabiamente chama de a estrutura da experiência, em que experiência significa correr contra o outro encontrando algo que não podíamos antecipar, esperar, prever ou ter antecipadamente, algo que tira nosso fôlego (CAPUTO, 1997, p. 162).

Em Derrida "não existe linguagem sem a dimensão performativa da promessa" (DERRIDA, 1996, p. 82). A linguagem do constitucionalismo assim como a linguagem da democracia é, em si mesma, promessa e agonistas. No constitucionalismo, a promessa da Constituição e sua efetivação através do exercício de direitos; na democracia, a promessa como a sempre presente possibilidade de renovação dos direitos e de abertura, eis que a democracia pressupõe a possibilidade de sua própria desconstrução. Porém, se em Derrida a democracia se caracteriza sempre como algo por vir (e neste sentido como promessa, a sua impossível realização no presente e também o seu paradoxo - pois a sua realização implicaria na dissolução das suas condições de possibilidade), a linguagem do constitucionalismo em alguma medida aprisiona o futuro no aqui e agora, a possibilidade da justiça contida no direito - o que em Derrida é uma impossibilidade. Assim, pensar o constitucionalismo como promessa importa também em pensar a justiça fora ou além do direito, a justiça enquanto experiência aporética, a experiência do que nós não somos capazes de experimentar (DERRIDA, 1990, p. 946).

A Constituição também é promessa enquanto impulso constituinte e, assim, se relaciona à democracia, na medida em que, conforme afirma Negri (2002, p. 07), "na era moderna os dois conceitos foram quase sempre correspondestes e estiveram unidos num processo histórico que, com a aproximação do século $\mathrm{XX}$, fez com que se identificassem cada vez mais". Tal promessa, impulso ou força constituinte, impede que a Constituição se esgote nas amarras rígidas do direito (ou do constitucionalismo) como fonte de produção das normas constitucionais. Ainda que o constitucionalismo diga respeito à limitação do poder constituinte e da democracia e, assim, se autoimponha um fechamento, este será sempre provisório e tenso. Isto, pois, a Constituição como promessa e a Constituição efetiva, assim como o poder constituinte, a democracia e o constitucionalismo experimentam uma permanente e inerradicável tensão.

A democracia como promessa, como abertura insuscetível de aprisionamento, la démocracie a venir, não é a democracia que será realizada amanhã ou democracia futura. Conforme Derrida (1996, p. 83), a democracia pressupõe o reconhecimento da irredutibilidade da promessa quando, no momento messiânico, it can come / ça peut venir. Assim como ocorre com o poder constituinte, a promessa da democracia é, ao mesmo tempo, um sobrestamento, uma suspensão, o que não se decide, como também um impulso para a Constituição real, efetiva, para o decidível. 
Na sua relação com o tempo o poder constituinte é sua suspensão, mas também sua aceleração. $O$ poder constituinte se opõe ao constitucionalismo como governo limitado pelo direito. A limitação do poder pelo direito e, da mesma forma, o controle sobre o governo não se encaixam em um impulso constituinte (o tempo presente) sendo, precisamente, o oposto, a coisa constituída (o tempo passado). O tempo, em seu presente contínuo, constituiu um novo tempo que não somente redime o tempo passado, mas o transforma. O constitucionalismo limitado à uma ideia de Constituição é sempre uma olhar para o passado, ou seja, o tempo passado juridicamente constituído, a menos que ele retenha o impulso constituinte (a promessa).

Uma Constituição radical é aquela que não se conforma aos mecanismos liberais de mútua negociação entre os poderes constituídos, arriscando-se a ser mais do que isso, ou seja, objeto e sujeito da política democrática. Os direitos estão na Constituição, na medida em que ela permite a sua constante reinvenção e demanda (dos direitos). Uma Constituição radical não sintetiza a tensão entre poder constituinte (democracia) e poderes constituídos: ela é precisamente isso, a tensão! Neste sentido, devemos interpretar a conhecida afirmação de Sieyès, "a Constituição, antes de mais nada, pressupõe um poder constituinte", como a Constituição se pressupõe como poder constituinte (AGAMBEN, 1998, p. 40-41)2.

Daí a força da Constituição, especialmente de uma Constituição radical, na medida em que é a primeira ordem que se (auto)impõe como manifestação do poder constituinte e da soberania popular, comprometendo ambos. Explorar as suas possibilidades e dificuldades é a tarefa a que me proponho neste artigo, assim como do seu significado inferido dos eventos ocorridos recentemente - 2011, 2012 e 2013) em vários países no mundo e, em particular, no Brasil. Refiro-me à chamada Primavera Árabe, aos protestos na Espanha, em Portugal e na Grécia contra as medidas de austeridade econômica impostas pela União Europeia; à ocupação de Wall Street em Nova Iorque, etc.; e às chamadas jornadas de junho no Brasil, que, a despeito de questionar o preço da tarifa de ônibus em vários estados da federação brasileira, desencadearam uma onda de manifestação e protestos diversos.

\section{PODER CONSTITUINTE E PODER SOBERANO}

Conforme Jacques Derrida (1990, p. 991), o pensamento moderno tardio sobre o poder soberano - do final do século XIX ao século XX - reagiu às definições

2 Sieyes (1970, p. 180-181) fala, no capítulo 5, do Quést-ce que tiers état? Dans chaque partie la constitution n'est pas l'ouvrage du pouvoir constitué, mais du pouvoir constituent. 
abstratas e às análises formais da soberania. A fundação da maior parte dos Estados se deu como consequência de uma situação que podemos, genericamente, chamar de revolucionária. Revolucionária no sentido de que uma nova ordem jurídica foi instaurada, sobretudo, num contexto terrível e de violência e não sem grande sofrimento. Como diz Derrida, as revoluções são elas mesmas ininterpretáveis e indecifráveis na sua própria violência.

Para a ciência do direito, o poder constituinte é tradicionalmente a fonte da qual a nova ordem constitucional emana. É o poder de fazer a nova Constituição, da qual os poderes constituídos adquirem a sua estrutura. Desta perspectiva o poder constituinte instala uma ordem jurídico-constitucional totalmente nova.

Contemporaneamente, o poder constituinte é rediscutido por Antonio Negri, para quem este não se manifesta apenas como fonte onipotente e expansiva que produz normas constitucionais, mas como sujeito dessa produção, dessa atividade igualmente onipotente e expansiva (NEGRI, 2002, p. 07-08). Negri mostra como a tarefa de ordenar o poder constituinte enquanto sujeito da política e para a política democrática é complexa.

Negri (2002, p. 07-08) cita Burdeau para mostrar como o poder constituinte apresenta, do ponto de vista jurídico, uma dificuldade excepcional dada a sua natureza híbrida. A potência do poder constituinte é avessa a uma integração total em um sistema hierarquizado de normas e competências, permanecendo sempre estranho ao direito. É um poder que funda o direito, mas se opõe a sua fundação. Essa dificuldade se acentua ainda mais pelo fato de a democracia ser rebelde à constitucionalização (NEGRI, 2002, p. 07-24, 207-208). Vale dizer, a democracia é a teoria do governo absoluto, ao passo que o constitucionalismo é a teoria do governo limitado, da democracia limitada, contida nas fronteiras que ela própria criou. Do ponto de vista jurídico o poder constituinte é a fonte de produção das normas constitucionais. Paradoxalmente é um poder que surge do nada e organiza todo o direito. No entanto, deve ser temporalmente limitado, encerrado numa factualidade (NEGRI, 2002, p. 07-09).

Pois bem, ao compreender o lugar da soberania como um lugar de indistinção entre o dentro e o fora, como uma zona de inerradicável tensão, torna-se então, possível, pensá-la em termos do poder constituinte sem qualquer sacrifício mútuo (CHUEIRI, 2005, p. 138).

Conforme Negri (2002, p. 26), o poder constituinte não emana de poder constituído algum; não é uma instituição do poder constituído. É antes um ato de escolha, a determinação radical que descortina um horizonte ou, ainda, 
se trata do radical dispositivo de algo que ainda não existe e cujas condições de existência pressupõem que o ato criador não perca suas características na criação (AGAMBEN, 1998, p. 43; CHUEIRI, 2005, p. 136).

Na gramática da ciência jurídica, o poder constituinte significa onipotência, onipresença e nenhuma limitação. Entretanto, esses significados são sacrificados pela pragmática, pelo uso dessa gramática que, ao contrário, exerce uma espécie de domesticação do poder constituinte. Dessa forma, a Constituição, criada pelo poder constituinte e para a democracia, mostra-se como obstáculo do próprio poder constituinte e da própria democracia (da soberania popular) (NEGRI, 2002, p. 07-08).

É preciso recuperar esta ideia e esta práxis de que o povo, soberano, ao se autolegislar, cria e funda a Constituição, através de toda radicalidade que está em tal ato fundante, impondo a si mesmo as regras e limites que vão regular os seus poderes constituídos. Ainda, a ideia de que o ato fundante e constituinte não se dissolve depois que a Constituição está feita, mas nela permanece como o seu traço político próprio, aquilo que não alivia a sua (da Constituição) responsabilidade em relação à democracia e aos direitos fundamentais: seja no momento da sua aplicação, seja no momento da sua própria revisão.

Tanto Agamben quanto Negri remetem à filosofia primeira, ao livro Theta, da Metafísica de Aristóteles (1984, p. 181), na qual o autor se refere ao Ser não como uma entidade fixa, mas como um vir-a-ser, um Ser em transformação ou em movimento. A fonte dessa transformação é dynamis, a qual não se confunde com aquilo que muda, a entidade fixa. Neste sentido da dynamis aristotélica, o poder constituinte pode ser pensado não como completamente emancipado da soberania, mas como uma potencialidade constituinte. Na mesma medida em que potencialidade não (pre)domina (sobre) a atualidade, ao contrário, nesta se dissolve, pois ambas são modos do Ser primeiro, o poder constituinte não (pre) domina (sobre) a soberania ou esta se dissolve naquele. A soberania retém a sua potencialidade ou seu poder constituinte, porém, na forma de uma suspensão. Segundo Agamben (1998, p. 44), por isso é tão difícil pensar uma Constituição da potencialidade inteiramente livre do princípio da soberania como um poder constituinte que tenha definitivamente quebrado com o bando que o liga ao poder constituído.

Volto, então, ao problema inicial, isto é, a difícil e paradoxal relação entre constitucionalismo e democracia, (re)tomada agora como a relação entre o poder constituído e o poder constituinte. Diferentemente de Negri, entendo que é 
possível conceber que o constitucionalismo, ao invés de frear o poder constituinte, o exibe, o expõe e o reafirma quando garante, protege e renova os compromissos democráticos, sobretudo através da realização da Constituição. Isso acontece quando, por exemplo, o constitucionalismo garante o direito dos que protestam ainda que isto, paradoxalmente, lhe imponha o ônus do enfretamento de seus limites. Se por um lado, para Negri, o constitucionalismo sempre se refere ao passado, por outro, ele acontece no presente, não como mera repetição do passado, mas como condição para o exercício dos direitos, isto é, como condição para a ação política e, assim, o constitucionalismo abre perspectivas para o futuro. $\mathrm{Ou}$ seja, pode/deve também o constitucionalismo olhar para o presente e ter vistas ao futuro. E isso ocorre justamente nesses momentos de concretização radical dos compromissos democráticos (através da Constituição).

Em um trabalho da década de 1980, o professor francês Claude Lefort se referiu à democracia como um processo constante de reinvenção de direitos (LEFORT, 1981). Neste sentido, contra todas as formas de totalitarismo, ele defende uma revolução democrática, cuja principal característica é o conflito, o qual não deve, de forma alguma, ser erradicado da sociedade.

É também preciso pensar o sentido dos conflitos, que, ao mesmo tempo, supõem o fato do poder e a busca de uma consideração das diferenças no Direito (LEFORT, 1981, p. 62). Esses conflitos constituem cada vez mais as especificidades das sociedades democráticas modernas. Desta forma, a democracia inaugura a experiência de uma sociedade inapreensível, indomesticável, na qual o povo é dito soberano, mas também não cessa de questionar sua identidade, na qual aquela permanecerá latente (LEFORT, 1981, p. 118).

Os protestos - e isto remete aos acontecimentos de 2011, 2012 e 2013 anteriormente mencionados - evidenciam não somente os conflitos (políticos, sociais, econômicos, culturais, etc.), mas demandam a todo tempo e de todas as formas uma sociedade mais justa e igualitária. Eles reafirmam a potência do poder constituinte na concreção dos direitos fundamentais e com isso renovam o constitucionalismo.

A tensão entre poder constituinte e poder constituído tem de ser entendida, nesse contexto tenso, agonístico, como um sinal vigoroso no sentido de uma sociedade radicalmente democrática. Se é o poder constituinte um impulso, ele funda a Constituição, mas nela permanece em tensão com os poderes constituídos. Esses poderes, aos quais chamemos de constitucionalismo, defenderão e resguardarão a própria Constituição, não porque formalmente ela se impõe como norma fundamental (Kelsen) ou como decisão política fundamental (Schmitt), 
mas porque, conforme Derrida, se a democracia está por vir, isto requer uma ação política no presente.

Nessa dynamis entre poder constituinte e poder constituído, democracia e constitucionalismo, a Constituição, por exemplo, a brasileira de 1988, não pode ter a sua temporalidade datada no dia de sua promulgação, assim como não pode ser datado o poder constituinte no momento da formação da Assembleia Constituinte em 1987. Poder constituinte e Constituição devem ser pensados como um processo, como acontecimentos, isto é, lutas e reivindicações; o tempo dos eventos. Por isso é indesejável datar o poder constituinte que deu origem à atual Constituição da República no Brasil em $1^{\circ}$ de fevereiro de 1987; tampouco é desejável encerrálo no dia da promulgação da Constituição, em 5 de outubro de 1988. O poder constituinte, como potência constituinte, se manifestou muito antes de $1^{\circ}$ de fevereiro de 1987 e ainda está presente na própria Constituição. Vale dizer, no exemplo recente da história constitucional brasileira, o poder constituinte (como potência) remonta aos movimentos ou ações empreendidos pela sociedade civil brasileira, iniciados em 1985, e reaparece, como força, toda vez que se pretende atingir a nossa Constituição com golpes. Os movimentos de junho de 2013 demonstram isso.

Neste sentido, poder soberano e poder constituinte, poder constituinte e poder constituído estabelecem uma dinâmica que possibilita a instauração e a manutenção de uma Constituição radical. Vista de outra perspectiva, essa dinâmica ou esse movimento refere-se à capacidade de o povo se autolegislar e fundar a ordem normativa que lhe regerá. Porém, a potência desse ato nele não se esgota. Ao se impor uma Constituição e, com isso, se constituir como comunidade política, o povo exige, ao mesmo tempo, que tal Constituição seja agonisticamente vivida e experimentada. Para tanto, limites são, paradoxalmente, estabelecidos ao poder soberano do povo.

\section{CONSIDERAÇÃ̃ FINAIS: \\ CONSTITUCIONALISMO E DEMOCRACIA (RADICAIS)}

Se o constitucionalismo significa limites à soberania popular, então, alguns conteúdos da Constituição devem permanecer fora do alcance da decisão majoritária ou das deliberações democráticas. Eis o paradoxo que marca a democracia constitucional e que precisa ser enfrentado, se o que pretendemos é radicalizar a Constituição.

Segundo Negri, (2002, p. 24-26) a Constituição se apresenta como fórmula transcendente, pois se remete sempre ao processo político (poder constituinte) que 
a instituiu. Ela apresenta-se como imanente, pois se reafirma a cada aplicação de suas normas. Acrescentamos ainda, a sua contingência na medida da eventualidade do poder constituinte, o qual é, ao mesmo tempo, necessário e inevitável. Pois bem, ao invés de apelar para fórmulas jurídicas ou políticas de superação do caráter paradoxal da Constituição em relação ao poder constituinte e à soberania, seria melhor reconhecer e aceitar a ausência de pressupostos regulatórios e plenitude de potência. $\mathrm{O}$ que nos interessa sublinhar é a oposição, apontada por Negri, entre a democracia, como forma política do poder constituinte, e o constitucionalismo, enquanto aquilo que o limita e ao fazê-lo nega a própria democracia. Entretanto, tal oposição não pode nos desiludir ou acanhar diante da articulação, ainda que precária, entre constitucionalismo e democracia. Ao contrário, parto do pressuposto (e nisto é que estou insistindo) que a tensão entre ambos é altamente produtiva.

Uma Constituição radical deve reter a ideia de potência, de impulso constituinte. Porém, diferentemente do que aponta Negri - e aqui retome-se o que disse anteriormente-, acredito que é a partir da aplicação da própria Constituição, a partir da concretização dos direitos nela previstos, que se pode atualizar e revigorar sua potência, sua carga revolucionária, no Estado Constitucional Democrático. A potência revolucionária da Constituição aparece quando ela é aplicada, quando ela é também decisão política fundamental e, assim, fundamenta decisões políticas e jurídicas, digamos, de uma segunda ordem, que garantem direitos e seu exercício, inclusive o direito de dizer que uma norma constitucional é inconstitucional e, por isso mesmo, deve ser desobedecida.

Aqui reside o recuo da minha fala, mas também o seu avanço, isto é, a afirmação de Benjamin de que o Estado de exceção se tornou paradigma de governo ou, conforme Paulo Arantes, em sua intervenção oral, é aquele a expressão das relações centro-periferia na nova ordem global imperial. Pois bem, é isso que constitui a possibilidade da ação política da rua e na rua, esta potência, essa carga revolucionária que só adquire sentido em seu movimento e como algo que está por vir/to come.

Política e direito, democracia e constitucionalismo enredados em um movimento contínuo, perpassados por uma necessária decisão sobre o que não se é possível decidir. A política e o direito enquanto momentos da decisão e o indecidível como a própria possibilidade do agir e do decidir. No dizer de Caputo (1997, p. 137), “a tomada da decisão, o julgamento, dependem do indecidível pois é esta condição que nos dá algo para decidir". Se queremos radicalizar a Constituição, 
é necessário que esta seja efetivamente resultado de uma decisão, que vá além do calculável, do programável e, nesse ir além, a Constituição se mantém como promessa.

É por essa razão que a Constituição e a democracia, enquanto promessa, contêm a radicalidade que abala os horizontes estáveis das nossas expectativas, transgredindo o possível e o concebível, indo além do que é visível e previsível e que não é propriedade de algum povo escolhido, mas de todos. Assim, é desde a promessa que o real se instala. Se os trabalhos constituintes se articulam no âmbito das promessas, é justamente aquilo que a Constituição reteve da potência constituinte que dá a dimensão da sua efetividade. Em outras palavras, não é o fato de uma ou outra norma constitucional ter ou não ter sido aplicada e produzido seus efeitos, ter ou não ter sido regulamentada, ao longo desses vinte e cinco anos, que nos permite falar sobre a efetividade da Constituição. $O$ efetivo é justamente esse caráter radical que a Constituição reteve do poder constituinte e que nos permite, em nome da democracia e do constitucionalismo, lutar e reivindicar direitos e reinventá-los a todo momento na rua e a partir da rua.

Entretanto, o agora, o tempo presente da Constituição só pode ser compreendido na sua relação com o passado e o futuro. Neste sentido, o tempo da Constituição é o da sua aplicação, é o tempo do evento, do acontecimento, no que isso envolve passado, presente e futuro; é o tempo dos movimentos.

Tentando responder à pergunta se é possível uma Constituição radical, eu diria que sim, na perspectiva de uma democracia, de um constitucionalismo e de uma justiça por vir, por acontecer, a venir, to come. Radicalizar a Constituição importa em radicalizarmos nossas ações, no sentido da transformação, da refundação e refundição do direito e da política, chamando a nossa atenção sempre para o agora, esse núcleo imodificável do tempo passado, presente e futuro. Não há história que seja um catálogo cronológico de fatos, como não há constituinte e Constituição cujo sentido se torne refratário aos eventos em suas continuidades e descontinuidades. Ainda, a Constituição é promessa precisamente porque nos faz agir, isto é, se realiza através da intervenção permanente de seus destinatários, que são, ao mesmo tempo, seus realizadores, ou seja, nós. Os movimentos recentes de junho de 2013 no Brasil são exemplares no sentido do que nos constituem e, por isso mesmo, nos fazem agir. São igualmente exemplares quando corporificam o encontro do constitucionalismo com a democracia, como promessa e como real efetivação; quando são radicais, pois, a um só tempo, relativos ao que está na origem, na raiz, como ao que está desemparelhado, instável e promove reações em cadeia. 


\section{REFERÊNCIAS}

AGAMBEN, Giorgio. Homo sacer: sovereign power and bare life. Trans. Daniel Heller-Roazen. Stanford: Stanford University Press, 1998.

. Estado de exceção. Tradução de Iraci D. Pleti. São Paulo: Boitempo, 2004.

ARANTES, Paulo. Extinção. São Paulo: Boitempo, 2007.

ARISTÓTELES. The complete works. Edited by Jonathan Barnes. Princeton, New Jersey: Princeton University Press, 1984. v. I e II.

BRAGA, Ruy. Sob a sombra do precariado. In: MARICATO, Ermínia et al. Cidades rebeldes: passe livre e as manifestações que tomaram as ruas do Brasil. São Paulo: Boitempo/Carta Maior, 2013. p. 79-82.

CAPUTO, John (Ed.) Deconstruction in a nutshell. New York: Fordham University Press, 1997.

CHUEIRI, Vera Karam de. Before the law: philosophy and literature. Michigan: Proquest/UMI, 2005.

DERRIDA, Jacques. Force of Law: the mystical foundation of authority. Cardozo Law Review, 11: 5-6 (July/August) 1990.

. Remarks on deconstruction and pragmatism. In: MOUFFE, Chantal. Pragmatism and deconstruction. New York/London : Routledge, 1996.

LEFORT, Claude. A invenção democrática. Tradução de Isabel Loureiro. São Paulo: Brasiliense, 1981.

MARICATO, Ermínia et al. Cidades rebeldes: passe livre e as manifestações que tomaram as ruas do Brasil. São Paulo: Boitempo/Carta Maior, 2013.

MOUFFE, Chantal. The democratic paradox. London/New York: Verso, 2000.

NEGRI, Antonio. Poder constituinte: ensaio sobre as alternativas da modernidade. Rio de Janeiro: DP\&A, 2002.

OCCUPY: movimentos de protesto que tomaram as ruas. Tradução de João Alexandre Peschaski. São Paulo: Boitempo/Carta Maior, 2012.

ROLNIK, Raquel. As vozes das ruas: as revoltas de junho e suas interpretações. In: MARICATO, Ermínia et al. Cidades rebeldes. passe livre e as manifestações que tomaram as ruas do Brasil. São Paulo: Boitempo/Carta Maior, 2013. p. 06-12.

SIEYES, Emmanuel. Qu'est-ce que le Tiers état? Genève: Libraire Droz, 1970.

ZIZEK, Slavoj. Problemas no paraíso. In: MARICATO, Ermínia et al. Cidades rebeldes: passe livre e as manifestações que tomaram as ruas do Brasil. São Paulo: Boitempo/Carta Maior, 2013. p. 101-108.

Recebido: 05/12/2013 